\title{
O USO DE MARKETING DIGITAL EM BIBLIOTECAS
}

\author{
Juliana Aparecida Gulka \\ Mestra em Gestão de Unidades de Informação \\ Universidade Federal de Santa Catarina \\ juliana.gulka@ufsc.br \\ Elaine Rosangela de Oliveira Lucas \\ Doutora em Ciência da Informação \\ Universidade do Estado de Santa Catarina \\ lanilucas@gmail.com \\ Elisa Cristina Delfini Correa \\ Doutora em Sociologia Política \\ Universidade do Estado de Santa Catarina \\ elisacorrea61@gmail.com
}

\begin{abstract}
Resumo
O presente artigo de revisão busca refletir sobre o espaço de atuação da biblioteca, principalmente no âmbito do mundo globalizado, que integra pessoas e instituições a partir do ambiente digital. Para isso, apresenta brevemente a evolução da biblioteca enquanto instituição custodiadora de acervos até a unidade de informação com foco primordial na disseminação da informação e do conhecimento, contando, para isso, com o aporte da Biblioteconomia e da Ciência da Informação. Contextualiza o surgimento do computador e o uso da internet como marcos, até se chegar à Web 2.0 e suas ferramentas. Defende que a tecnologia aponta para uma modificação do 'fazer' das bibliotecas, que podem romper barreiras de espaço e tempo, e utilizar aspectos do marketing para que sejam atingidas e satisfeitas as necessidades dos interagentes. A biblioteca deve considerar a junção do marketing com a tecnologia e o design, para definir boas estratégias de atuação em um cenário digital irreversível, evoluindo no trato com seus interagentes reais e potenciais, e levando em consideração a interação na implantação e melhorias de produtos e serviços.
\end{abstract}

\section{Palavras-chave}

Biblioteca. Web 2.0. Marketing Digital.

\section{INTRODUÇÃO}

As bibliotecas já foram consideradas 'depósitos do conhecimento', o que, em sua trajetória histórica, representa um lugar de silêncio, ao qual acessam os favorecidos social e intelectualmente. Embora em alguns locais essa percepção ainda exista, felizmente essa versão um tanto fechada da biblioteca tem mudado para um ambiente mais amigável, no qual o importante não é mais o acervo de livros em si, e sim a informação.

A reinvenção da biblioteca é pautada por novos parâmetros de comunicação, socialização e, principalmente, acesso à informação. Parte da influência pelas mudanças pode ser atribuída à tecnologia: com evolução rápida e tornando-se cada vez mais acessível, alavanca o acesso à informação de qualquer lugar, feito por qualquer pessoa. Os avanços transformam a vida das pessoas $\mathrm{e}$ seu cotidiano, à medida que sites, blogs, redes sociais e aplicativos mudam os comportamentos e a forma de os indivíduos se comunicarem. O computador conectado à internet proporciona uma capacidade de comunicação entre indivíduos nunca antes imaginada e, a partir disso, muda-se a "organização, identidade, conversação e mobilização social" (RECUERO, 2009, p. 16).

De acordo com dados do Comitê Gestor da Internet no Brasil (2014), em 2013 
o país contava com a metade da população conectada à internet, chegando a $51 \%$ - o que correspondia a 85,9 milhões de brasileiros naquele ano. As tecnologias da informação e comunicação (TIC), aliadas ao acesso cada vez maior a equipamentos como computador, celulares e tablets, além das facilidades de adesão à banda larga e wifi, possibilitaram a adoção da internet como parte do dia a dia da população.

Nesse contexto, sob influência significativa das TIC, é natural que a biblioteca comece a tentar extrapolar seus limites físicos, indo além das paredes de seu prédio. Muito além de apenas oferecer um catálogo em linha, a biblioteca precisa existir digitalmente, pois mesmo que ela não faça nada intencionalmente, os interagentes ${ }^{1}$ podem levá-la de alguma forma para a web, seja comentando em redes sociais ou publicando fotos e críticas em algum site. Cabe à unidade de informação aproveitar as oportunidades que o mundo digital oferece e marcar sua presença, e, para isso, pode contar com a ajuda de estratégias de marketing.

O marketing está ligado diretamente à área de Administração, no entanto, tem muito a contribuir com a biblioteca a partir do momento em que esta busca identificar e atender à necessidade dos interagentes, não como um processo automático, e sim planejado, centrado no ser humano e nas suas vivências e expectativas. Aliado às TIC, temse o marketing digital, que é explorado ainda timidamente pelas bibliotecas brasileiras.

Aliando as tecnologias ao marketing, tem-se uma visão clara de que há muito a explorar, e que a biblioteca não precisa ficar confinada a processos tradicionais de tratamento do acervo, mas pode extrapolar paredes à medida que está presente digitalmente.

A proposta deste artigo de revisão é refletir sobre o marketing no espaço de atuação da biblioteca, apresentando, para isso um breve percurso da literatura da área que aborda o tema, e a influência do digital nesse contexto.

${ }^{1}$ Em lugar de "usuário", foi adotado o termo "interagente", proposto por Correa (2014), pois ele representa de maneira mais adequada a proposta deste artigo.

\section{BIBLIOTECAS E O CAMPO DA CI- ÊNCIA DA INFORMAÇÃO}

Algumas instituições foram, por muito tempo, consideradas o templo do saber, um 'depósito' no qual se guardavam todos os registros do conhecimento, tendo seu acesso limitado aos detentores de tal honra, em sua maioria eruditos, além da elite de cada época. É a partir daí que começam as atividades de gestão de coleções, a princípio com foco na salvaguarda desses materiais, independentemente do suporte. De acordo com Araújo (2014), o que chamamos atualmente de biblioteca, arquivo e museu deriva da época dessas instituições, que se dedicaram a guardar documentos.

A biblioteca clássica, por assim dizer, possuía o foco na guarda de documentos, seu arranjo e ordenação. Guardar e preservar era mais importante do que disseminar a informação ali contida. Do período do Renascimento e posteriormente a transição até a Idade Moderna, surgem tratados e manuais que estabelecem regras para as instituições que guardam acervos. Esse processo avança e, no século XIX, há uma grande ênfase na sistematização das regras de tratamento técnico desses acervos - e é aí que se observa o surgimento formal das disciplinas de Arquivologia, Biblioteconomia e Museologia, como ciências relacionadas aos acervos nessas instituições (ARAÚJO, 2014).

Paralelamente, a Documentação se preocupava em não apenas custodiar os acervos informacionais, mas também promover os registros desses acervos de forma a maximizar o seu acesso, construindo inventários dos documentos espalhados em diferentes instituições. Iniciou-se então a preocupação em identificar o que cada instituição possuía, a fim de facilitar a sua localização, resultando no surgimento das bibliografias e de nomes como Otlet e La Fontaine. Araújo (2014, p. 4) afirma que "o objetivo dos dois era a construção de um grande movimento cooperativo, em nível planetário, para que fosse estabelecida uma espécie de 'inventário' de toda a produção humana de conhecimento registrado". 
Com o passar do tempo, porém, devido ao aumento da produção de publicações, o controle bibliográfico foi se tornando mais difícil, ao mesmo tempo que grupos especializados começavam a organizar informações de forma independente, atendendo a suas demandas locais. Soma-se a isso a evolução científica e tecnológica, na qual se passa a perceber que, definitivamente, guardar e ordenar coleções é importante, mas disponibilizar e disseminar informações é crucial e indispensável. Com o uso da tecnologia, "aumentaram as possibilidades de acesso, de guarda, de compartilhamento justamente pelo desprendimento da materialidade" (ARAUJO, 2014, p. 8).

A biblioteca, que por muito tempo foi considerada o templo do saber, único e intocável, foi se transformando. Precisou adaptar-se às mudanças físicas e tecnológicas dos suportes informacionais e de seu acesso. Com isso, veio também a explosão informacional, a dificuldade em recuperar informações cada vez mais dispersas e a Ciência da Informação.

autora), as

Para Russo (2010, p. 48, grifo da

[...] necessidades cada vez mais prementes dos usuários, em obter informações relevantes, no menor tempo possível - apontaram para a necessidade de criação de uma nova área do conhecimento que priorizasse $\mathrm{o}$ atendimento ao usuário em suas necessidades informacionais; nesse contexto, surge a CIÊNCIA DA INFORMAÇÃO.

A Ciência da Informação "é uma ciência interdisciplinar derivada de campos relacionados, tais como a Matemática, Lógica, Linguística, Psicologia, Ciência da Computação, Engenharia da Produção, Artes Gráficas, Comunicação, Biblioteconomia, Administração, e outros campos científicos semelhantes" (BORKO, 1968 , p. 2), que se consolida a partir do momento em que se preocupa não com o suporte físico dos documentos, mas com a sua "circulação, sua disseminação, a promoção de seu uso da maneira mais produtiva possível" (ARAUJO, 2014, p. 10). Para Capurro (2003), a Ciência da Informação tem uma raiz na Biblioteconomia clássica e outra na Computação Digital.

Apesar de alguns autores aterem-se aos chamados paradigmas da Biblioteconomia e salientarem o foco no suporte físico e nas práticas de desenvolvimento de coleções, e os da Ciência da Informação ao movimento da informação em um sistema de comunicação humana, com ênfase em tecnologia e na interdisciplinaridade, resgata-se aqui a reflexão de Sambaqui (1978), apontada e comentada por Russo (2010, p. 56):

[...] a Biblioteconomia gerou a Bibliografia, esta gerou a Documentação, que por sua vez gerou a Ciência da Informação. Se a paráfrase retrata ou não a verdadeira gênese das áreas nomeadas, o que se apreende é que a relevância maior da interrelação dessas disciplinas repousa no fato de que todas - cada uma com as suas especificidades - têm a finalidade de facilitar o acesso ao volume cada vez mais crescente da produção de conhecimento no mundo. Os estudiosos dessas áreas - bibliotecários, documentalistas, cientistas da informação, devem desempenhar papéis cada vez mais próximos da informação e mais distantes do suporte do livro ou do documento e, acima de tudo, devem voltar seus esforços para que os conteúdos por eles disseminados sejam utilizados cada vez mais a serviço da sociedade.

O que se percebe é a necessidade de a biblioteca acompanhar os movimentos da sociedade na busca pela informação, seja ela em formato físico ou digital. Em um momento no qual o excesso de informação e a carência por um filtro se fazem presentes, emerge a função principal de uma unidade de informação: disseminar o conhecimento.

A biblioteca tende a ser um espaço de inovação e criatividade, no qual se 
encontram aspectos interdisciplinares que dialogam entre si, e, acima de tudo, necessita compreender as mudanças promovidas pela tecnologia e salientadas pela Ciência da Informação como um caminho que visa promovê-la como uma instituição social, na disseminação da informação e conhecimento, na interação humana e no desenho de novos âmbitos profissionais aos bibliotecários.

\section{TECNOLOGIA E WEB 2.0}

Desde que o computador foi inventado, a vida cotidiana tem passado por várias transformações, isso sem levar em conta tudo que a tecnologia, de um modo geral, reflete: telefonia, áudio, vídeo, mobilidade, realidade virtual, nanotecnologia, internet, conectividade, globalização. A mistura de tudo isso (e um pouco mais), que às vezes até foge à compreensão humana, resulta em um mundo digital.

O nascimento da rede mundial de computadores em 1969 foi o início do que seria uma revolução. A internet, mais especificamente, teve sua expansão e difusão a partir da década de 1990, após a criação da tecnologia de hipermídia World Wide Web (SIQUEIRA, 2008), e influenciou significativamente não apenas a forma como as informações são disponibilizadas, mas as interações humanas a partir dela. De acordo com Siqueira (2008, p. 129), "a internet é um dos maiores inventos do século XX e o primeiro serviço a quebrar a barreira de um bilhão de usuários em menos de dez anos". Como se pode imaginar, a comunicação se tornou mais rápida e eficiente, além de aumentar $\mathrm{o}$ número de conexões entre pessoas com interesses em comum. Para Capurro e Hjorland (2007, p. 149), "embora o conhecimento e a sua comunicação sejam fenômenos básicos de toda a sociedade humana, é o surgimento da tecnologia da informação e seus impactos globais que caracterizam a nossa sociedade como uma sociedade da informação".

Essas mudanças no cenário tecnológico, com a evolução nas relações sociais e as transformações nos fluxos de informação, possibilitaram, além da convergência - aqui entendida como a fusão de três grandes áreas da tecnologia da informação e comunicação: computadores, comunicação e conteúdo (SIQUEIRA, 2008) -, o surgimento de novos ideais de colaboração, interação e participação, o que se denominou de Web Colaborativa.

Em meados de 2004, surge o conceito de Web 2.0, na qual as páginas de internet deixam de ser estáticas para se tornarem interativas, onde a criação e a colaboração são bem-vindas, ao contrário do que era feito até então, com os usuários somente consumindo. De acordo com Primo (2007, p. 1), “a Web 2.0 é a segunda geração de serviços online e caracteriza-se por potencializar as formas de publicação, compartilhamento e organização de informações, além de ampliar os espaços para a interação entre os participantes do processo".

Segundo O’Reilly (2005), há que se trabalhar a web como uma plataforma e aproveitar a inteligência coletiva, como o uso da folksonomia e até mesmo de hiperlinks, por exemplo. De acordo com o autor, a contribuição dos usuários é uma peça-chave para a Web 2.0.

Primo $(2007$, p. 4) destaca que

a partir de recursos da Web 2.0, potencializa-se a livre criação e a organização distribuída de informações compartilhadas através de associações mentais. Nestes casos importa menos a formação especializada de membros individuais. A credibilidade e relevância dos materiais publicados é reconhecida a partir da constante dinâmica de construção e atualização coletiva.

No entanto, o autor salienta que não se pode pensar a web como um espaço mágico, onde não existe ou não haja a necessidade de nenhum tipo de regulamentação ou cuidado, já que o coletivo também pode ser alvo de elementos mal-intencionados em relação ao trabalho feito pelos outros.

De qualquer forma, a Web 2.0 influenciou significativamente a dinâmica social. Os envolvidos nesse ambiente de troca não 
podem mais ser considerados apenas usuários, mas sim participantes, ou, ainda, interagentes. Corrêa (2014, p. 28) também reflete sobre o termo interagente no âmbito da Biblioteconomia e Ciência da Informação, propondo que "[...] parece ser este mais adequado para definir o cidadão contemporâneo que busca informação de maneira autônoma, inclusive nas bibliotecas."

Nesse contexto, no qual o usuário passa a ser interagente, a utilização da tecnologia e de ferramentas da Web 2.0 pela biblioteca contribui de forma significativa não apenas para a dinamização de seu espaço de atuação, mas também pela quebra da limitação espaço-temporal. Serviços e produtos estáticos que antes eram oferecidos apenas localmente podem também ser fornecidos virtualmente ou via acesso remoto, ou seja, há a expansão da oferta de recursos informacionais pela biblioteca, sem a necessidade de os interagentes se dirigirem ao seu espaço físico, podendo contar com processos inovadores de provimento de serviços e produtos digitais.

Com essa adequação, surge a possibilidade de o interagente contribuir para a criação ou melhoria de serviços e produtos, o que, feito sob a demanda da necessidade real, facilita a administração de recursos e atende às expectativas do público, resultando no cumprimento da missão da biblioteca.

Recursos como websites, blogs, redes sociais e sites de compartilhamento de vídeos e fotos são apenas alguns exemplos do que a tecnologia e a internet podem oferecer nos dias de hoje. Para se ter uma ideia, a proporção de pessoas que usam a internet todos os dias passou de $53 \%$ em 2008 para $71 \%$ em 2013. Os indicadores destacam também que $77 \%$ dos usuários de internet participam de redes sociais como o Facebook ou Google + e que $85 \%$ das pessoas com 10 anos de idade ou mais usam telefone celular, o que chega ao montante de 143 milhões de brasileiros (COMITÊ GESTOR DA INTERNET, 2014).

Isso significa que estamos vivenciando a era da conectividade. O que as bibliotecas precisam pensar é como elas podem estar presentes digitalmente, quais estratégias deverão ser utilizadas para a sua promoção no mundo digital e quais as possibilidades de se tornar uma biblioteca ubíqua.

O marketing é um dos caminhos que podem fornecer estratégias para as bibliotecas promoverem seus espaços de atuação e inovarem seus produtos e serviços, sempre buscando satisfazer e priorizar as necessidades e as carências informacionais dos interagentes.

\section{MARKETING E BIBLIOTECAS}

A história do marketing é construída sob vários conceitos, e essa atividade evoluiu, com o passar do tempo, do foco ao produto ao foco no cliente. Oficialmente, o marketing surgiu nos Estados Unidos, mas somente após a Segunda Guerra Mundial começou a ser aceito em outros locais. No Brasil, esse termo só começou a ser usado em 1954, superando a palavra 'mercadologia', utilizada até então (KARKOTLI, 2008).

Um conceito de 1997, atribuído a Philip Kotler, define marketing como "o processo de planejamento e execução desde a concepção, preço, promoção e distribuição de ideias, bens e serviços para criar trocas que satisfaçam aos objetivos de pessoas e organizações" (KARKOTLI, 2008, p. 2). O mesmo autor definiu ainda, em 2006, que "o marketing envolve a identificação e a satisfação das necessidades humanas e sociais" (KOTLER, 2006, p. 4).

No âmbito da Biblioteconomia e da Ciência da Informação, é preciso pensar o marketing voltado às instituições sem fins lucrativos e, mais especificamente, a bens intangíveis. Dessa forma, a biblioteca deveria considerar seu planejamento com foco nos interagentes e no desenvolvimento de produtos e serviços de forma inovadora, melhorando a estrutura organizacional e facilitando os fluxos de informações, uma vez que "o marketing é considerado um instrumento gerencial da unidade de informação, visto como um negócio, assim como qualquer outro, de qualquer natureza." (AMARAL, 2007, p. 22).

Nas palavras de Oliveira (1994, p. 11), "mais que uma troca comercial envol- 
vendo valores monetários, marketing é uma interação social e troca de valores que venham a satisfazer algumas das necessidades de ambos os partidos - biblioteca e usuários". Silveira (1987, p. 7) explica que "as bibliotecas que objetivam despertar, provocar ou garantir trocas de informação onde estas não existem e estimular trocas onde já existem [...] estão desenvolvendo uma função de marketing, saibam disto ou não."

Essa relação de troca pressupõe que as duas partes estejam interessadas e que haja algo a ser ofertado, por uma parte ou pela outra, havendo benefício mútuo. A relação de troca abordada vai ao encontro da sociedade conectada na qual vivemos atualmente, com interagentes, e não mais usuários, que utilizam recursos da web para participar, e não apenas consumir informações, conteúdos e conhecimento. Esse espaço está extremamente evidente e, portanto, ressalta ainda mais a necessidade de o bibliotecário usufruir de conceitos e técnicas de marketing nas unidades de informação.

Da mesma forma que outras áreas do conhecimento, o marketing foi se transformando com o passar do tempo, sofrendo influências sociais, econômicas e tecnológicas, passando por três fases, chamadas de marketing 1.0, 2.0 e 3.0. O primeiro, 1.0, está relacionado, sobretudo, a Era Industrial, onde o principal objetivo era vender os produtos. O segundo, 2.0, surgiu durante a Era da Informação, na qual as TIC são consideradas o seu núcleo, e os clientes tornam-se informados e com características e necessidades mais específicas. Já o terceiro, marketing 3.0, é centrado no ser humano, no qual "as empresas diferenciam-se por seus valores", sendo um "marketing colaborativo, cultural e espiritual" (KOTLER; KARTAJAYA; SETIAWAN, 2010, p. 5).

O marketing 3.0 foi impulsionado principalmente pela crescente onda tecnológica, que atualmente significa, em termos simples, "computadores e celulares baratos, Internet de baixo custo e fonte aberta" (KOTLER; KARTAJAYA; SETIAWAN, 2010 , p. 7). Esses fatores permitem a colaboração dos indivíduos entre si, sua expressão, interação e participação. A partir disso, três marcos passam a influenciar diretamente o marketing 3.0, centrado no ser humano: a participação, a globalização e a sociedade criativa.

Em relação ao marketing impulsionado pela tecnologia, Amaral (2007, p. 22, grifo nosso) salienta que
são poucos os estudos fundamentados em teoria sobre o uso das técnicas mercadológicas no setor de informação. $O$ uso de técnicas de marketing em diversos tipos de unidades de informação, ou até mesmo $o$ uso de marketing na era da informação eletrônica, do marketing cultural e da promoção da informação também são pouco explorados na literatura de Ciência da Informação brasileira.

Essa afirmação, feita dez anos atrás, evidenciava que havia uma lacuna na discussão de estratégias e possibilidades da utilização do marketing pelas bibliotecas no mundo em que vivemos. Se as demais organizações, principalmente mercadológicas, estão pensando no ser humano como centro, em que a sua contribuição, socialização, criatividade e conectividade são quesitos a serem considerados na elaboração de estratégias (nesse caso principalmente digitais), a biblioteca, então, deveria preocupar-se com isso também.

Em recente estudo desenvolvido por pesquisadoras da Universidade do Estado de Santa Catarina (UDESC) e da Universidade de São Paulo (USP) sobre a gestão da informação no serviço de referência, as pesquisadoras Lucas e Damian (2017) perceberam que os esforços do marketing em bibliotecas para melhorar a conscientização e promover o uso de recursos e serviços, sobretudo os eletrônicos, tiveram destaque na literatura analisada, assim como estratégias e planos específicos do marketing para aumentar a visibilidade do material de referência. As autoras evidenciaram também, na literatura analisada, algumas experiências de unidades de informação que adotam a Estratégia Multi-pronged, usando mais de 20 técnicas de marketing para promover seus recursos. 
A evolução do conceito de marketing, bem como seu envolvimento no mundo das bibliotecas e serviços de informação, é apresentada por Gonzalez (2015a). A diferença entre estratégia e tática em marketing digital é analisada, e as tendências que os especialistas consideram mais seguras a curto prazo são estudadas, bem como os desafios que essas tendências apontam às bibliotecas. Em outro estudo, Gonzalez (2015b) evidencia os benefícios do marketing digital para bibliotecas apresentando três estudos de caso de campanhas de marketing em bibliotecas universitárias espanholas e demonstrando como alcançaram seus objetivos de crescimento do uso da coleção ou serviços.

Já Diprince (2016) aponta a necessidade da publicitação dos serviços das bibliotecas universitárias para os alunos, indicando o valor potencial desses recursos. Um dos tópicos abordados trata exclusivamente sobre a dicotomia impressão versus marketing digital.

De forma mais ampla, a obra editada por Mckenzie e Martin (2014), bibliotecários da Edge Hill University (Inglaterra), apresenta alguns estudos de caso de bibliotecas da Grã-Bretanha, Austrália e Canadá, examinando os papéis mutantes dos bibliotecários e observando como a inserção no ambiente digital impactou os profissionais no desenvolvimento de habilidades, conhecimentos e nos comportamentos necessários para operar as TIC. Estrutura-se de forma temática, tendo como uma das vertentes: repensando o marketing e a comunicação, na qual são analisadas as abordagens e práticas estratégicas para aproveitamento das mídias sociais, ilustrando a importância das atividades de comunicação e marketing nesses novos espaços on-line.

Tendo como tema, junto ao marketing, o uso de mídias sociais e diferentes espaços de colaboração na internet, temos a publicação de Bishop e Rowley (2013), que investigam a abordagem de marketing e a promoção adotada por bibliotecas no Reino Unido, especificando o desenvolvimento de sua presença digital. Esse estudo indica que as bibliotecas podem se beneficiar ao se comunicar com os interagentes de maneiras adequadas aos seus objetivos, incluindo o uso de sites, e-mail e Web 2.0.

Mazzocchi (2014) analisa a tendência de uso de ferramentas de marketing digital e aponta que os blogs das bibliotecas (especialmente os blogs de bibliotecas acadêmicas) estão enfrentando a explosão das redes sociais. A relação entre blogs e redes sociais e as ferramentas de comunicação da biblioteca também é analisada. Sakas e Sarlis (2016) apresentam um modelo para uso do Twitter por bibliotecas, para promoção de seus serviços, que combina uma visão teórica da Ciência da Informação e do marketing com uma ferramenta prática. Russo (2017) discute o marketing da biblioteca, enfocando especificamente uma mudança das relações públicas tradicionais para o marketing digital centrado no cliente. Os tópicos incluem: a) o impacto das mídias sociais na capacidade das empresas de se envolverem diretamente com os clientes; b) a importância de distinguir um público-alvo específico para o mercado; e c) a diferença entre promoção e engajamento.

Alguns autores, como Shea (2015), apontam a importância da avaliação regular da biblioteca de seus recursos de marketing. De maneira a verificar quais esforços de marketing ainda estão funcionando. $\mathrm{O}$ documento também analisa a forma como instituições similares ofertam seus programas e serviços, propondo uma reflexão sobre se essas táticas também podem funcionar para outras unidades de informação.

Levando em consideração que a tecnologia foi e está sendo amplamente adotada pela população, é indispensável que a biblioteca repense também suas estratégias, sua imagem e sua presença na web. A partir disso, tem-se o marketing digital, que engloba conceitos, plataformas e estratégias, a fim de desenvolver ações no cenário digital emergente. É importante ressaltar que, mesmo que o marketing utilize o ambiente digital e on-line para promover estratégias, ainda é interessante coordená-las com ações em um ambiente tradicional, pois, apesar de toda a evolução tecnológica que ocorre dia após dia, o ser humano ainda vive em um ambiente híbrido. 
Gabriel (2010) relaciona algumas plataformas digitais que são utilizadas para o desenvolvimento de estratégias digitais de marketing e podem ser consideradas - pelo menos em parte - como recursos para a promoção da biblioteca. São elas: a) páginas digitais (sites, portais, blogs e perfis); b) e-mail; c) realidades mistas (realidade aumentada, virtualidade aumentada, realidade virtual); d) tecnologias mobile (RFID, mobile tagging, SMS/MMS, Bluetooth, apps, mobile TV); e) plataformas digitais de redes sociais; f) plataformas digitais de busca (Google, Yahoo, Bing, Alpha, etc.); g) games e entretenimento digital; h) tecnologias inteligentes de voz; i) vídeo/TV digital/ vídeo imersivo.

Trata-se de verificar as possibilidades e acompanhar não apenas as tendências existentes, mas espaços de atuações distintos da biblioteca. Os dados apesentados anteriormente apontam que o público está aderindo cada vez a recursos e plataformas digitais, com o uso intenso de computadores, tablets e celulares e mantendo-se conectado à internet. Essas plataformas podem ser utilizadas para desenvolver ações combinadas com estratégias digitais, mantendo a presença digital da biblioteca.

A presença digital é a "existência de algo (seres humanos, marcas, empresas, coisas, etc.) no ambiente digital", conforme apontado por Gabriel (2010, p. 249), e são os conteúdos que fazem essa representação. Não ter presença digital significa não existir na internet, e esse é justamente o caminho inverso ao qual a biblioteca deve tomar, principalmente em dias nos quais o perfil do consumidor de informação ultrapassa as barreiras do tempo e do espaço e apresenta características 3.0, como afirma Corrêa (2016).

O consumidor de informação 3.0 está constantemente conectado à internet, tem preferência por textos mais curtos e de acesso imediato e exige informação personalizada, entre outras características apontadas pela autora. Para esse tipo de interagente, a biblioteca estritamente ou essencialmente analógica possui pouco valor.

A biblioteca, portanto, carece de um olhar mais atento aos indivíduos, a fim de criar produtos e serviços que facilitem suas vidas, e, nesse contexto, entra a questão de estar onde o interagente está: em dispositivos móveis, que são leves e permitem a resolução de coisas e a pesquisa de informações de modo rápido e fácil, ou seja, a utilização da tecnologia mobile; em redes sociais, tanto para compartilhamento de conteúdo quanto para comunicação (incluindo o Facebook, Twitter, Instagram, YouTube, WhatsApp, etc.); além da utilização de aplicativos para Android e IOS.

Gabriel (2010) ressalta ainda que, para o desenvolvimento de uma boa estratégia de presença digital, é preciso se preocupar com o tripé: marketing, tecnologia e design $(\mathrm{M}+\mathrm{T}+\mathrm{D})$. Essa combinação, se bem aplicada, tem o objetivo de propiciar o posicionamento e os objetivos ideais para a organização, além de fornecer a estrutura para a sua implantação e a oferta de conteúdo ideal para o público-alvo.

Aquelas bibliotecas que já possuem algum tipo de presença on-line podem utilizar-se de um ponto de partida para a elaboração de planejamentos e estratégias de marketing, no entanto, ressalta-se que um website ou a existência de um catálogo on-line não seja exatamente a presença digital ideal, embora seja o mínimo esperado atualmente.

\section{CONSIDERAÇÕES FINAIS}

O percurso da biblioteca, desde que era um espaço de custódia de acervos até tornar-se o local onde se prioriza o acesso às informações, independentemente do suporte, recebeu, em algum momento, a influência das tecnologias.

Atualmente, essa influência tecnológica abrange a sociedade de forma contundente, por meio do uso de dispositivos capazes de processar informações de forma rápida e eficaz. Soma-se a isso a adoção da internet cada vez maior pela população, e tem-se uma forma de comunicação tão rápida e eficiente nunca imaginada.

A Biblioteconomia e a Ciência da Informação, com a junção de seus paradigmas, têm a possibilidade de ajudar as bibliotecas a prosperar nesse mundo digital, ao mesmo 
tempo que busca a interdisciplinaridade em outras ciências, por meio da adoção de ferramentas e processos para promover inovações.

O marketing, vindo principalmente do campo da Administração, é uma dessas opções que propõem a melhoria da experiência do interagente em relação a sua satisfação com a biblioteca e o que ela oferece.

Quando juntadas as estratégias de marketing em plataformas consideradas fenômenos digitais, a exemplo das mídias sociais, o que se espera é a evolução da maturidade das unidades de informação no trato com os indivíduos reais e potenciais.

É também irreversível esse cenário, o que mostra que a busca pelo novo e a capacitação do bibliotecário não só no uso de ferramentas tecnológicas, mas também na gestão a partir delas e com elas são aspectos relevantes a serem considerados. Esse trabalho buscou fazer uma breve exposição da possibilidade de a biblioteca utilizar os conceitos de marketing com o propósito do investimento em recursos que satisfaçam as necessidades e ambições do interagente. Não apenas isso, mas que considere sua interação' propriamente dita na construção de produtos e serviços, além da participação na melhoria daquilo já existente.

A utilização de ferramentas digitais e estratégias de marketing pela biblioteca pode ajudar a instituição a prosperar e melhorar as experiências que proporciona. Essa proposta precisa ser melhor explorada, com mais aprofundamento, a fim de proporcionar o embasamento e o estudo necessários à aplicação das tendências de marketing digital nas bibliotecas.

\title{
THE USE OF DIGITAL MARKETING IN LIBRARIES
}

\begin{abstract}
The present review article seeks to reflect on the space of the library, especially in the globalized world, which integrates people and institutions from the digital environment. In order to do so, it briefly presents the evolution of the library as a custodian institution of collections to the information unit with a primary focus on dissemination of information and knowledge, counting on the contribution of Librarianship and Information Science. Contextualizes the emergence of the computer and the use of the internet as landmarks, until reaching web 2.0 and its tools. He argues that the technology points to a modification of the 'do' of libraries, which can break down barriers of space and time, and use marketing aspects to be met and met with the needs of the interactors. The library should consider linking marketing with technology and design to define good strategies for acting in an irreversible digital landscape, evolving in dealing with its actual and potential interactors, and taking into account the interaction in the deployment and improvement of products and services.
\end{abstract}

Keywords

Library. Web 2.0. Digital marketing.

Artigo recebido em 21/11/2017 e aceito para publicação em 02/05/2018

\section{REFERÊNCIAS}

AMARAL, S. A. Marketing e Inteligência competitiva: aspectos complementares da gestão da informação e do conhecimento. In: __ (Org.). Marketing na Ciência da Informação. Brasília: Ed. da UNB, 2007. p. 19-31.

ARAUjO, C. A. Á. O que é Ciência da Informação? Informação e Informação, Londrina, v. 19, n. 1, p. 1-30, jan./abr.

2014.Disponivel em:
$<$ http://www.uel.br/revistas/uel/index.php /informacao/article/view/15958>. Acesso em: $1^{\circ}$ fev. 2016.

BISHOP, T.; ROWLEY, J. Digital marketing in independent libraries in the united kingdom. Journal of Librarianship and Information Science, London, v. 45. n. 4, p. 323-334, Jul. 2012. doi: http://dx.doi.org/10.1177/09610006124534 73.

BORKO, H. Information Science: what is it? American Documentation, Washing- 
ton, v.19, n. 1, p. 3-5, jan. 1968. (Tradução Livre)

CAPURRO, R. Epistemologia e Ciência da Informação. 2003. Disponível em: $<$ http://www.capurro.de/enancib_p.htm>. Acesso em: 1 fev. 2016.

.; HJORLAND, B. O conceito de informação. Perspectivas em Ciência da Informação, Belo Horizonte, v.12, n. 1, 2007. Disponível em:

$<$ http://portaldeperiodicos.eci.ufmg.br/ind ex.php/pci/article/view/54>. Acesso em: 16 jan. 2016.

COMITÊ GESTOR DA INTERNET NO BRASIL. Pesquisa sobre o uso das tecnologias de informação e comunicação no Brasil: TIC Domicílios e Empresas 2013. São Paulo: Comitê Gestor da Internet no Brasil, 2014. Disponível em:

<http://www.cetic.br/media/docs/publicac O-

es/2/TIC_DOM_EMP_2013_livro_eletroni co.pdf>. Acesso em: 23 jan. 2015.

CORRÊA, E. C. D. Consumidor de informação 3.0. In: PRADO, J. M. K. (Org.).

Ideias emergentes em Biblioteconomia. E-book. São Paulo: FEBAB, 2016. p. 60-68. Disponível em:

$<$ https://ideiasemergentes.files.wordpress.c om/2016/03/ideiasemergentesembiblioteco nomia2.pdf>. Acesso em: 31 mar. 2016.

.Usuário, não! Interagente. Proposta de um novo termo para um novo tempo.

Encontros Bibli, Florianópolis, v. 19, n. 41, p. 23-40, dez. 2014. Disponível em:

$<$ https://periodicos.ufsc.br/index.php/eb/ article/view/15182924.2014v19n41p23>.

Acesso em: 1 fev. 2016.

DIPRINCE, E. et al. Don't panic! Reference \& User Services Quarterly, Williamsburg, VA, v. 55, n. 4, p. 283-292, 2016.

GABRIEL, M. Marketing na era digital: conceitos, plataformas e estratégias. São Paulo: Novatec, 2010.
GONZÁLEZ-FERNÁNDEZ-

VILLAVICENCIO, N. Qué entendemos por usuario como centro del servicio. Estrategia y táctica en marketing. El Profesional de la Información, Barcelona, v. 24, n. 1, p. 5-13, jan. 2015.

ROI en medios sociales: campañas de marketing en bibliotecas. Social media profitability: marketing campaigns in libraries.E1 Profesional de la Información, Barcelona, v. 24, n. 1, p. 22-30, jan. 2015. HANNABUSS, S. A dictionary of marketing. 4th edition. Reference reviews, Bingley, v. 30, n. 8, p. 15-16, 2016.

KARKOTLI, G. Marketing para iniciantes. Curitiba: Camões, 2008.

KOTLER, P. Administração de marketing. 12. ed. São Paulo: Pearson, 2006.

KOTLER, P.; KARTAJAYA, H.; SETIAWAN, I. Marketing 3.0: as forças que estão definindo o novo marketing centrado no ser humano. Rio de Janeiro: Elsevier, 2010.

LUCAS, E. R. O.; DAMIAN, I. P. M. Gestão da Informação no serviço de referência: análise de publicações. In: ENCONTRO NACIONAL DE PESQUISA EM CIÊNCIA DA INFORMAÇÃO, 18., 2017, Marília. Anais... Marília: ANCIB, 2017. No prelo.

MAZZOCCHI, J. Blogs and social networks in libraries: complementary or antagonistic tools? Library Philosophy and Practice, Moscow (EUA), n. 1, p. 1-12, 2014.

MCKENZIE, A.; MARTIN, L (Eds.). Mastering digital librarianship: strategy, networking and discovery in academic libraries. London: Facet, 2014.

OLIVEIRA, S. M. Marketing em bibliotecas: por que relutar? Revista de Biblioteconomia e Comunicação, Porto Alegre, v. 6, p. 9-16, jan./dez. 1994. 
O'REILLY, T. What is Web 2.0: design patterns and business models for the next generation of software. 2005. Disponível em:

<http://www.oreillynet.com/pub/a/oreilly /tim/news/2005/09/30/what-is-web20.html>. Acesso em: 5 jan. 2016.

PRIMO, A. O aspecto relacional das interações na Web 2.0. E- Compós, Brasília, v. 9 , p. 1-21, 2007.

RECUERO, R. Redes sociais na internet. Porto Alegre: Sulina, 2009. Disponível em: $<$ http://www.ichca.ufal.br/graduacao/bibli oteconomi-

a/v1/wpcontent/uploads/redessociaisnainte rnetrecuero.pdf>. Acesso em: 23 fev. 2016.

RUSSO, L. Mastering marketing. Library Journal, v. 142, n. 4, p. 46-48, mar. 2017.
RUSSO, M. Fundamentos em Biblioteconomia e Ciência da Informação. Rio de Janeiro: E-papers, 2010.

SAKAS, D. P.; SARLIS, A. S. Library promotion methods and tools modeling and simulation on twitter. Library Review, Louisville, v. 65, n. 6, p. 479-499, 2016.

SHEA, E. Taking stock of your institution's marketing efforts. Reference \& User Services Quarterly, Williamsburg, VA, v. 54, n. 3, p. 27-29, Spring 2015.

SILVEIRA, A. Introdução. In: (Org.). Marketing em bibliotecas e serviços de informação: textos selecionados. Brasília: IBICT, 1987. p. 5-13.

SIQUEIRA, E. Para compreender o mundo digital. São Paulo: Globo, 2008. 